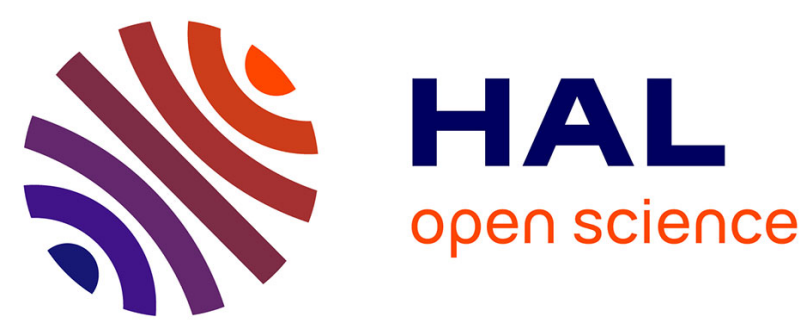

\title{
Impact of clouds on the estimation of daily evapotranspiration from MODIS-derived instantaneous evapotranspiration using the constant global shortwave radiation ratio method
}

\author{
Yazhen Jiang, Ronglin Tang, Xiaoguang Jiang, Zhao-Liang Li
}

\section{To cite this version:}

Yazhen Jiang, Ronglin Tang, Xiaoguang Jiang, Zhao-Liang Li. Impact of clouds on the estimation of daily evapotranspiration from MODIS-derived instantaneous evapotranspiration using the constant global shortwave radiation ratio method. International Journal of Remote Sensing, 2019, 40 (5-6), pp.1930-1944. 10.1080/01431161.2018.1482025 . hal-02377686

\section{HAL Id: hal-02377686 \\ https://hal.science/hal-02377686}

Submitted on 9 Dec 2020

HAL is a multi-disciplinary open access archive for the deposit and dissemination of scientific research documents, whether they are published or not. The documents may come from teaching and research institutions in France or abroad, or from public or private research centers.
L'archive ouverte pluridisciplinaire HAL, est destinée au dépôt et à la diffusion de documents scientifiques de niveau recherche, publiés ou non, émanant des établissements d'enseignement et de recherche français ou étrangers, des laboratoires publics ou privés. 


\title{
Impact of clouds on the estimation of daily evapotranspiration from MODIS derived instantaneous evapotranspiration using the constant global shortwave radiation ratio method
}

\author{
Yazhen Jiang ${ }^{1,2}$, Ronglin Tang ${ }^{3,1,}$ *, Xiaoguang Jiang ${ }^{1,4, ~ *}$, Zhao-Liang Li ${ }^{5,2}$
}

1. University of Chinese Academy of Sciences, Beijing 100049, China;

2. Icube (UMR7357), UdS, CNRS, 300 Bld Sébastien Brant, CS10413, Illkirch 67412, France;

3. State Key Laboratory of Resources and Environment Information System, Institute of Geographic Sciences and Natural Resources Research, Chinese Academy of Sciences, Beijing 100101, China;

4. Key Laboratory of Quantitative Remote Sensing Information Technology, Academy of OptoElectronics, Chinese Academy of Sciences, Beijing 100094, China;

5. Key Laboratory of Agri-informatics, Ministry of Agriculture/Institute of Agricultural Resources and Regional Planning, Chinese Academy of Agricultural Sciences, Beijing 100081, China;

* Authors to whom correspondence should be addressed: tangrl@lreis.ac.cn, xgjiang@ucas.ac.cn

\begin{abstract}
Upscaling instantaneous evapotranspiration (ET), retrieved at a specific satellite overpass time, to a daily scale is a key issue in drought monitoring, water resource management and climate change study. The constant global shortwave radiation ratio method, which maintains a constant ratio of incoming global shortwave radiation to ET during the diurnal cycle, is reported to be robust when temporally upscaling instantaneous ET. However, this temporal upscaling method is typically used on clear-sky days. This study aims to evaluate cloud effects on the constant global shortwave radiation ratio method for extrapolating instantaneous ET from MODIS (Moderate-Resolution Imaging Spectroradiometer) and ancillary data to daily scale at the Yucheng station in China. Partly cloudy-sky (clear during satellite transit) and clear-sky days were selected using measured downward global shortwave irradiances; each partly cloudy-sky had a hypothetical clear-sky counterpart. Then, daily ET was estimated by extrapolating the instantaneous ET using the constant global shortwave radiation ratio method under clear-sky, partly cloudy-sky and hypothetical clear-sky conditions. The results showed that (a) upscaled ET for clear-sky days had a bias of $-4.3 \mathrm{Wm}^{-2}$ and a root mean square error (RMSE) of $14.5 \mathrm{Wm}^{-2}$, and upscaled ET on partly cloudy-sky days had a bias of $-7.8 \mathrm{Wm}^{-2}$ and an RMSE of $18.9 \mathrm{Wm}^{-2}$, with more serious underestimations under partly cloudy-sky conditions, and (b) daily ET obtained under partly cloudy-sky conditions were reduced due to cloud effects comparing with that under hypothetical clear-sky conditions.
\end{abstract}

Key words: Evapotranspiration, constant global shortwave radiation ratio method, cloud effect

\section{INTRODUCTION}

Evapotranspiration (ET) can be used to express the vegetation water consumption and reflect the surface moisture effectively (Delogu et al., 2012; Anderson et al., 2012; Tang et al., 2017a). 
Daily ET is more significant in drought monitoring, water resources management and climate change study, compared to instantaneous ET from remote-sensing based models at the time of satellite overpass (Chávez et al., 2008; Li et al., 2009; Tang et al., 2013, 2017b). Therefore, the remotely sensed instantaneous ET must be temporally upscaled to obtain ET integration over a longer time scale (e.g., days, months and years). To accommodate the temporal scaling challenges encountered by remote-sensing based ET models, various schemes have been proposed and applied to upscale instantaneous ET to daily value (Chávez et al., 2008; Cammalleri et al., 2014; Wandera et al., 2017). These methods usually assume the self-preservation of the ratios between ET and a given reference variable during daytime hours (Crago, 1996; Bastiaanssen et al, 2000; Delogu et al., 2012).

ET variability during the daily course is influenced by variation of the radiation energy received at the surface (Brutsaert and Sugita, 1992; Crago, 1996). Downward solar shortwave radiation forms a majority of the radiation energy (Mallick et al., 2015; Barzin et al., 2017). By using the downward shortwave radiation as a reference variable and assuming that the ratio of the downward shortwave radiation to ET remains constant during a diurnal cycle, the constant global shortwave radiation ratio method was developed (Ryu et al., 2012; Van Niel et al., 2012; Xu et al., 2015). Xu et al (2015) compared this method with four other temporal upscaling methods and suggested that the constant global shortwave radiation ratio method was one of the best performing schemes in deriving daily ET. Recently, Wandera et al (2017) proposed an artificial neural network (ANN) algorithm to predict daily incoming shortwave radiation when using this temporal upscaling method across different terrestrial ecosystems. Overall, this method appears to be promising and has substantial potential for upscaling instantaneous ET to daily value using satellite data for field and regional-scale ET studies.

However, the constant global shortwave radiation ratio method is typically used for clear-sky days, and studies regarding cloud effects on daily ET estimation with this method are extremely rare. However, the cloud coverage is a prominent phenomenon in many parts of the world (Bussieres and Goita, 1997); and the clear-sky assumption is not always appropriate for upscaling remote-sensing based ET because the sky may be clear at one specific time during the day whereas it might be cloudy for the other part of the day (Jackson et al., 1983; Wandera et al., 2017). Thus, extrapolating instantaneous ET only under clear-sky days has limited the operational remote sensing applications. Therefore, investigating cloud effects on the instantaneous ET extrapolation is critical for understanding and improving the temporal upscaling method to obtain accurate daily ET estimations.

This study evaluates the cloud effects on the constant global shortwave radiation ratio method in extrapolating instantaneous ET to the daily scale. The instantaneous ET is retrieved from MODIS (Moderate-Resolution Imaging Spectroradiometer) data combining a few ancillary meteorological measurements from the Yucheng station in China. The study period spans from late April 2009 to late October 2010. Partly cloudy-sky (clear during satellite transit) and clear-sky 
days are selected using measured downward global solar radiation; each partly cloudy-sky day has a corresponding hypothetical clear-sky day. Daily ET is obtained by extrapolating the instantaneous ET using the constant global shortwave radiation ratio method for selected clear-sky, partly cloudy-sky and hypothetical clear-sky days.

\section{TEST SITE AND DATA}

\subsection{Test site}

The test site where remote sensing data and ground based variables are collected is the Yucheng station $\left(36.8291^{\circ} \mathrm{N}, 116.5703^{\circ} \mathrm{E}\right)$, which is part of the Chinese terrestrial ecosystem flux research network and a significant site aiming to measure the long-term exchange of carbon dioxide, water vapor and heat between the land and the atmosphere across different terrestrial ecosystems in China. The Yucheng station locates southwest of Yucheng County in the Shandong Province of Northern China (Figure 1). The area has a subhumid monsoon climate, with a mean annual temperature of $13.1{ }^{\circ} \mathrm{C}$ and a mean annual precipitation of $528 \mathrm{~mm}$. The soil type is classified as sandy loam. The annual crops include winter wheat, which is seeded in mid-October and harvested in mid-June, and summer corn, which is seeded in late-June and harvested in early October.

[Insert Figure 1 about here]

\subsection{MODIS data}

MODIS products are used to estimate the instantaneous ET at a specific time of MODISTerra overpass. These products include the calibrated radiance product (MOD021KM), the land surface temperature and emissivity product (MOD11_L2), the surface reflectance product (MOD09GA), the geolocation product (MOD03) and the cloud mask product (MOD35). The MOD021KM product consists of calibrated and geolocated radiance and reflectance at the top of atmosphere (TOA) for 36 bands. The level 2 MOD11_L2 product is generated daily at 5 minute increments using the generalized split window algorithm with a $1 \mathrm{~km}$ spatial resolution to estimate the surface temperature. The MOD03 product is a dataset that mainly includes geodetic coordinates (latitude and longitude), solar zenith and azimuth angles, satellite zenith and azimuth angles, and ground elevation for each $1 \mathrm{~km}$ pixel, for the geo-calibration of the MOD11_L2 product. The MOD09GA is used to extract surface spectral reflectance for bands 1-7 to estimate the broadband surface albedo. The MOD35 product is used to guarantee the clear-sky identification.

\subsection{In-situ measurements}

The in-situ measurements used in this study include meteorological variables, radiation data, and flux data from late April 2009 to late October 2010, covering two phenological stages of the 
main crops (from the emergence to the harvest of winter wheat and summer corn) at the Yucheng station.

Meteorological variables, including air temperature and vapor pressure, are used as supplementary data together with MODIS products for the instantaneous ET and other parameter calculations. The radiation data include 5 minute averaged downwelling shortwave radiation used for clear-sky identifications, and 30 minute averaged downwelling shortwave radiation used for the temporal upscaling of the instantaneous ET.

The flux data include latent heat flux (LE) and sensible heat flux $(\mathrm{H})$, which are measured regularly by an eddy covariance (EC) system. A series of data quality control steps using an online flux computation and post-field data programmes were conducted to obtain reliable EC-measured LE and H (Tang et al., 2013). These data were carefully checked to ensure data quality by removing data spikes and abnormalities $\left(\mathrm{H}\right.$ and LE less than $-100 \mathrm{Wm}^{-2}$ or greater than $700 \mathrm{Wm}^{-2}$ approximating the lower and upper limits of surface net radiation). Net radiation $\left(R_{\mathrm{n}}\right)$ and soil heat flux $(G)$ are collected with lysimeters and a soil heat flux plate, respectively. The EC measured surface energy components are subject to energy budget closure errors; namely, $R_{\mathrm{n}}-G>\mathrm{LE}+\mathrm{H}$ (Foken, 2008; Story et al., 2013). For the effective validation of the results, the Bowen ratio (BR) correction method is used in this study to correct the imbalance of surface energy measurements (Twine et al. 2000). In the BR correction method, the surface available energy is repartitioned into $\mathrm{H}$ and LE by conserving the original Bowen ratio measured by the EC. Daily averaged LE from 00:00 $\mathrm{h}$ to 24:00 $\mathrm{h}$ at local time measured by the EC and corrected by the BR method are used to validate the daily ET resulted from the temporal upscaling method under different conditions. The EC measured $\mathrm{H}$ was used in this study only for the correction of the imbalance of surface energy measurements.

\section{METHODOLOGY}

\subsection{Calculation of instantaneous ET}

In this paper, the calculation of instantaneous ET (LE, used interchangeably) is performed using the following equation (Boegh et al., 2002):

$$
\mathrm{LE}=\left(\rho c_{\mathrm{p}} / \gamma\right) \frac{e_{\mathrm{s}}^{*}-e_{\mathrm{a}}}{r_{\mathrm{s}}+r_{\mathrm{ae}}}
$$

where $\rho\left(\mathrm{kgm}^{-3}\right)$ is the air density, $\left.c_{\mathrm{p}}\left(\mathrm{Jkg}^{-1} \mathrm{~K}^{-1}\right)\right)$ is the specific heat of air, $\gamma\left(\mathrm{kPaK}^{-1}\right)$ is the psychrometric coefficient, $r_{\mathrm{s}}\left(\mathrm{sm}^{-1}\right)$ is the surface resistance, $r_{\mathrm{ae}}\left(\mathrm{sm}^{-1}\right)$ is the average aerodynamic resistance above the reference height, $e_{\mathrm{s}}^{*}(\mathrm{kPa})$ is the saturated vapor pressure at the evaporating front evaluated from surface temperature, and $e_{\mathrm{a}}(\mathrm{kPa})$ is the vapor pressure of the air above the canopy.

To calculate $r_{\mathrm{ae}}$ and $r_{\mathrm{s}}$, the method uses the following equations together with vapor pressure at the surface $\left(e_{\mathrm{s}}, \mathrm{kPa}\right)$. A detailed description of the theory and the development of the method 
can be found in Boegh et al. (2002). The input parameters for this method include the remotesensing based surface temperature $\left(T_{\mathrm{s}}, \mathrm{K}\right)$, net radiation $\left(R_{\mathrm{n}}, \mathrm{Wm}^{-2}\right)$, soil heat flux $\left(G, \mathrm{Wm}^{-2}\right)$, and ground measured air temperature $\left(T_{\mathrm{a}}, \mathrm{K}\right)$ and $e_{\mathrm{a}}$.

$$
\begin{aligned}
& r_{\mathrm{ae}}=\rho c_{\mathrm{p}} \frac{\left(T_{\mathrm{s}}-T_{\mathrm{a}}\right)+\left(e_{\mathrm{s}}-e_{\mathrm{a}}\right) / \gamma}{R_{\mathrm{n}}-G} \\
& r_{\mathrm{s}}=r_{\mathrm{ae}}\left(e_{\mathrm{s}}^{*}-e_{\mathrm{s}}\right) /\left(e_{\mathrm{s}}-e_{\mathrm{a}}\right)
\end{aligned}
$$

Remote-sensing based $T_{\mathrm{S}}$ is obtained from the MOD11_L2 product (Tang et al., 2008). The $R_{\mathrm{n}}$ is computed from both downward and upward shortwave and longwave radiations at the ground:

$$
R_{\mathrm{n}}=(1-\alpha) R_{\mathrm{g}}+\varepsilon_{\mathrm{s}} L_{\mathrm{d}}-L_{\mathrm{u}}=(1-r) R_{\mathrm{g}}+\varepsilon_{\mathrm{s}} \varepsilon_{\mathrm{a}} \sigma T_{\mathrm{a}}^{4}-\varepsilon_{\mathrm{s}} \sigma T_{\mathrm{s}}^{4}
$$

where $\alpha$ is the surface albedo, $R_{\mathrm{g}}\left(\mathrm{Wm}^{-2}\right)$ is the global solar radiation; $\varepsilon_{\mathrm{s}}$ is the surface emissivity; $L_{\mathrm{d}}\left(\mathrm{Wm}^{-2}\right)$ is the downward longwave radiation; $L_{\mathrm{u}}\left(\mathrm{Wm}^{-2}\right)$ is the upward longwave radiation; $\varepsilon_{\mathrm{a}}$ is the atmospheric emissivity; and $\sigma\left(\mathrm{Wm}^{-2} \mathrm{~K}^{-4}\right)$ is the Stefan-Boltzmann constant.

The $G$ is calculated by using a semi-empirical function of NDVI (Normalized Difference Vegetation Index) and $T_{\mathrm{s}}$ in this paper (Tang et al., 2013; Bastiaanssen et al., 1998):

$$
G / R_{\mathrm{n}}=\left(0.576-0.382(\mathrm{NDVI})-0.007\left(T_{\mathrm{s}}-273.15\right)\right)
$$

\subsection{The constant global shortwave radiation ratio method}

In the constant global shortwave radiation ratio method, the ratio of instantaneous incoming shortwave radiation to the daily value remains constant, which is equal to the ratio of instantaneous LE to the daily value, namely,

$$
\frac{\mathrm{LE}_{\mathrm{i}}}{\mathrm{LE}_{\mathrm{d}}}=\frac{R_{\mathrm{s}, \mathrm{i}}}{R_{\mathrm{s}, \mathrm{d}}}
$$

where $R_{\mathrm{s}}\left(\mathrm{Wm}^{-2}\right)$ is the downward shortwave irradiance, and the subscripts i and $\mathrm{d}$ represent the instantaneous and daily time scales, respectively. In this paper, the instantaneous $R_{\mathrm{S}}$ is the halfhourly averaged shortwave radiation measurements, and daily $R_{\mathrm{s}}$ is the averaged downward shortwave radiation measurement from 00:00 $\mathrm{h}$ to $24: 00 \mathrm{~h}$ at local time.

Specifically, during hypothetical clear-sky days, the ratio of instantaneous downward shortwave solar radiation to the daily value is expressed as (Bisht et al., 2005; Hou et al., 2014)

$$
\frac{R_{\mathrm{s}, \mathrm{i}}}{R_{\mathrm{s}, \mathrm{d}}}=\frac{\pi}{2} \sin \left(\pi\left(\frac{t_{\text {overpass }}-t_{\text {rise }}}{t_{\text {set }}-t_{\text {rise }}}\right)\right)
$$

where $t_{\text {rise, }}, t_{\text {set }}$ and $t_{\text {overpass }}$ represent the time for sunrise, sunset and the satellite overpass, respectively. 


\subsection{Clear-sky identification}

In this study, the 5 minute averaged downwelling shortwave radiations are used to identify clear-sky moments using the two-step method proposed by Long and Ackerman (2000).

On a clear-sky day, shortwave radiation reaches its maximum at local solar noon and diminishing to zero at night. The primary factor determining the magnitude at any given time is the solar zenith angle (Long et al, 2006). For a given solar zenith angle, the total shortwave radiation is expected to fall within a nominal range of values for clear-sky days. Thus, the first test for clear-sky identification is to normalize the total shortwave irradiance by a power law function of the cosine of the solar zenith angle Equation (8):

$$
R_{\mathrm{s}, \mathrm{N}}=R_{\mathrm{s}} / \mu_{0}^{\mathrm{b}}
$$

where $R_{\mathrm{s}, \mathrm{N}}\left(\mathrm{Wm}^{-2}\right)$ is the normalized total shortwave radiation, $\mu_{0}$ is the cosine of the solar zenith angle, and $\mathrm{b}$ is a constant. The maximum and minimum limits of the $R_{\mathrm{s}, \mathrm{N}}$ are set according to empirical variations of the measured downwelling shortwave radiation with the solar zenith angle of clear-sky days; only normalized values falling inside this range are tentatively labelled preliminary. The values used in this study are 1.31 for the constant $\mathrm{b}, 1150 \mathrm{Wm}^{-2}$ for the maximum limit, and $900 \mathrm{Wm}^{-2}$ for the minimum limit. Figure 2 shows the 5 minute total and normalized shortwave radiation from 20 May 2009.

\section{[Insert Figure 2 about here]}

The temporal variation of total shortwave irradiance is used for clear-sky identification in the second step. For clear-sky conditions, the absolute value of the $R_{\mathrm{s}}$ variation over a short period should be less than that of the top-of atmosphere irradiance $\left(\mathrm{TOA}_{\mathrm{i}}\right)$. The limit values of the variation are used based on the solar zenith angle according to the absolute change in $\mathrm{TOA}_{\mathrm{i}}$ over time. The maximum and minimum limit values are respectively set as the absolute value of the $\mathrm{TOA}_{\mathrm{i}}$ variation, plus or minus a factor that is a function of $\mu_{0}$ Equation (9).

$$
\begin{aligned}
& \mathrm{MIN}=\left|\Delta\left(\mathrm{TOA}_{\mathrm{i}}\right) / \Delta t\right|-\left[R_{\mathrm{t}}\left(\mu_{0}^{\text {noon }}+0.1\right) / \mu_{0}\right] \\
& \mathrm{MAX}=\left|\Delta\left(\mathrm{TOA}_{\mathrm{i}}\right) / \Delta t\right|+C \mu_{0}
\end{aligned}
$$

where $R_{\mathrm{t}}$ is the temporal resolution of the data in minutes, $\mu_{0}^{\text {noon }}$ is the solar zenith angle at local solar noon, and 0.1 is added to ensure a factor value greater than $R_{\mathrm{t}}$ at local solar noon. This formulation describes the physics of the decrease in the absolute value of the $R_{\mathrm{s}}$ variation at the longer atmospheric path lengths having small $\mu_{0}$ near sunrise and sunset. $C$ is a subjective constant based on clear-sky system noise $\left(2.0 \mathrm{Wm}^{-2}\right)$. Figure 3 shows the change values of top-of atmosphere irradiance and measured shortwave irradiance for 24 May 2009.

[Insert Figure 3 about here] 
Using the clear-sky identification method, clear-sky moments were identified. The satellite overpass moment must be clear for the instantaneous ET calculation with high-quality satellite data. Thus, the clear-sky moments were guaranteed by MOD35 data, in which the quality assurance (QA) flags in binary varied from " 00 " to " 11 " and only the "11" (highest quality without cloud) was chosen. Finally, 77 partly cloudy-sky (the satellite overpass moment is clear) days and 45 totally clear-sky days were selected. What needs illustration is that there are 77 corresponding hypothetical clear-sky days corresponding to the partly cloudy-sky days.

\section{RESULTS AND DISCUSSION}

\subsection{Instantaneous LE calculation results}

After the remote-sensing based $T_{\mathrm{s}}, R_{\mathrm{n}}$ and $G$ were calculated, the instantaneous LE was estimated by combining meteorological $T_{\mathrm{a}}$ and $e_{\mathrm{a}}$. Figure 4 (a) shows the instantaneous LE at MODIS-Terra overpass time (10:30) for 77 partly cloudy-sky days and 45 selected clear-sky days. The instantaneous LE was compared with the EC observations corrected by the BR method to close the energy imbalance of the measurements. It shows that the instantaneous LE of clear-sky days was overestimated by a small bias of $1.5 \mathrm{Wm}^{-2}$, with a root mean square error (RMSE) of $37.6 \mathrm{Wm}^{-2}$. The instantaneous LE of partly cloudy-sky days was seriously underestimated, by a bias of $-32.3 \mathrm{Wm}^{-2}$ and an RMSE of $49.9 \mathrm{Wm}^{-2}$. The reason for this systemic underestimation of instantaneous LE for partly cloudy-sky days may be that the BR correction method would not perform well under cloudy days. In addition, identification of clear-sky moment was based on 5 minute averaged shortwave radiations, but the temporal scale of instantaneous LE was half an hour. Thus, it may result in 5 minute cloudy periods during the half-hourly interval. To compare the upscaling results for partly cloudy-sky days and clear-sky days in next section, we corrected the instantaneous LE of partly cloudy-sky days by linear regression $(y=1.032 x+30.653)$ (Figure 4(b)). After the linear regression, the instantaneous LE of partly cloudy-sky days was overestimated by a small bias of $0.22 \mathrm{Wm}^{-2}$, with an RMSE of $39.9 \mathrm{Wm}^{-2}$, which had a similar accuracy with that under clear-sky days.

For the instantaneous LE under hypothetical clear-sky conditions, they were assumed to be equal to that under the corresponding partly cloudy-sky days. With the accommodation of instantaneous LE, daily LE values under partly cloudy-sky, clear-sky and hypothetical clear-sky conditions were obtained by upscaling the instantaneous LE obtained at the satellite overpass time through the constant global solar radiation ratio method.

[Insert Figure 4 about here]

\subsection{Daily LE of partly cloudy-sky days and clear-sky days}

The daily LE upscaled from instantaneous LE of 77 partly cloudy-sky and 45 clear-sky days were compared with the corresponding daily LE measurements corrected by the BR method. The comparison results are shown in Figure 5. It demonstrates that daily LEs for partly cloudy-sky 
days and selected clear-sky days were both underestimated. The upscaled and observed daily LEs for clear-sky days produced a significant linear relation, with an $R^{2}$ (coefficient of determination) of 0.96; the estimation bias and RMSE were $-4.3 \mathrm{Wm}^{-2}$ and $14.5 \mathrm{Wm}^{-2}$, respectively. The $R^{2}$ related to the estimated daily LE for partly cloudy-sky days was 0.92 , with a bias of $-7.8 \mathrm{Wm}^{-2}$ and an RMSE of $18.9 \mathrm{Wm}^{-2}$, respectively. The lower statistical bias and RMSE of daily LEs revealed superior performance of the temporal upscaling method under clear-sky conditions.

For clear-sky days, the daily LE were underestimated although the instantaneous LE was overestimated, and the underestimation of this method was also found in other studies (Tang et al., 2013). Under partly cloudy-sky conditions, the daily LE was still more seriously underestimated although the systemic underestimation of instantaneous LE was corrected. This indicated that clouds strengthen the underestimation of daily LE when using this temporal upscaling method.

[Insert Figure 5 about here]

Histogram statistics of the biases related to upscaled daily LE of 45 selected clear-sky days and 77 partly cloudy-sky days are shown in Figure 6. It demonstrates that the biases of daily LE related to most clear-sky days (about $8 \%$ ) were distributed from -20 to $0 \mathrm{Wm}^{-2}$. For the biases related to most partly cloudy-sky days (about $8 \%$ ), they were distributed from -35 to $-5 \mathrm{Wm}^{-2}$; this explains more serious underestimations of daily LE under partly cloudy-sky conditions.

[Insert Figure 6 about here]

\subsection{Daily LE of partly cloudy-sky days and hypothetical clear-sky days}

Daily LE of 77 hypothetical clear-sky days was obtained by upscaling instantaneous LE using the constant global solar radiation ratio method. These values were hypothetical daily LEs of hypothetical clear-sky days corresponding to partly cloudy-sky days. Under this condition, daily shortwave radiations were calculated according to the ratio of instantaneous incoming shortwave radiation to the daily value Equation (7). Figure 7 shows the variations of daily LE under partly cloudy-sky and corresponding hypothetical clear-sky conditions. It shows that daily LE under partly cloudy-sky conditions was reduced compared to that of hypothetical clear-sky days. Because incoming shortwave solar radiation is the main energy source in the LE process, the reduction of daily LE was considered to be caused mainly by the reduction of shortwave radiation on partly cloudy-sky days. The variations of daily LE over time complied with a periodicity law, showing greater variability during springtime, namely DOY (Day of year) from 111-166 in both 2009 and 2010, compared to other seasons. This may also result from seasonal variations of total shortwave radiation (Salgueiro et al., 2014).

[Insert Figure 7 about here]

\subsection{Discussion}

The cloud effect on the constant global solar radiation ratio method in temporal upscaling of instantaneous LE was evaluated in the preceding sections. As for the upscaling method, it is more suitable for upscaling instantaneous LE to daytime values, because night-time global solar 
radiation equals zero and makes no contribution to night-time and daily LEs. The analysis in this study is based on a daily period, meaning that the night-time LE contribution is implicitly considered, which may have introduced some mismatches. Another main limitation of this temporal upscaling method is that it cannot effectively incorporate the influence of horizontal advection and the variation of meteorological variables (e.g., wind speed and vapor pressure deficits) because the global solar radiation is less dependent on these meteorological variables.

Daily LEs were obtained by extrapolating instantaneous LE through the constant global solar radiation ratio method. Note that the instantaneous LE of MODIS-Terra overpass time on partly cloudy-sky days and clear-sky days were both estimated using remote sensing and meteorology data in this study. The parameter retrievals required for the instantaneous LE calculation had some deviations, which affected the daily LE estimation; namely, it affected the behaviour of the temporal upscaling method to some extent. Under partly cloudy-sky conditions, although the underestimation of instantaneous LE was corrected, the daily LE was still seriously underestimated. It showed that clouds strengthened the underestimation of daily LE when using this upscaling method. The reason is that clouds affected the constancy of the ratio between the instantaneous incoming shortwave radiation and the daily value and caused the reduction of the daily shortwave radiation as well. In addition, the upscaling results were both compared with the EC measurements after closing the energy imbalance with the BR correction methods, and the performance of the BR method would influence the validation of the results.

For the cloud effect evaluation, cloud types and characteristics were not taken into considerations in this study. In fact, different cloud types and characteristics would result in different influences on the variation of daily LE. Simply speaking, global solar radiation is the principal driver that controls daily LE variability, unless there is substantial diurnal asymmetry in cloudiness or an abrupt change in soil moisture; under persistent cloudy conditions, LE still scales with global solar radiation. Other authors have studied the variations of cloud effects on shortwave radiation for several sky conditions and specific types of clouds (Berg et al., 2011). Berg et al. (2011) found an average value of $245.5 \mathrm{Wm}^{-2}$ of cloud effect on the shortwave radiation for shallow cumuli. Therefore, the cloud types regarding more cloud characteristics (i.e., column water vapor amounts or aerosol optical depth changes) should be taken into consideration in future studies.

In addition, for the hypothetical clear-sky days corresponding to partly cloudy-sky days, daily LEs were obtained by using the constant global solar radiation ratio method, and the ratio was based on Equation (7), which depended on clear-sky moment selections. In a future study, a better choice might be to calculate the hypothetical clear-sky irradiances corresponding to each partly cloudy-sky using the radiative transfer equation (Mayer and Kylling, 2005). 


\section{CONCLUSION}

This study evaluated cloud effects on the constant global shortwave radiation ratio method for temporal upscaling of instantaneous ET from MODIS data at the Yucheng station in China. The study period spanned from late April 2009 to late October 2010. Using measured downward global irradiances, both partly cloudy-sky and clear-sky days were selected; each partly cloudysky had its own hypothetical clear-sky counterpart. Daily LE was obtained by upscaling the instantaneous LE using the constant global shortwave radiation ratio method for selected clear-sky, partly cloudy-sky and hypothetical clear-sky days. Comparing with observed daily LE corrected by the BR method, the upscaled LE under selected clear-sky conditions had a bias of $-4.3 \mathrm{Wm}^{-2}$ and an RMSE of $14.5 \mathrm{Wm}^{-2}$; under partly cloudy-sky conditions had a bias of $-7.8 \mathrm{Wm}^{-2}$ and an RMSE of $18.9 \mathrm{Wm}^{-2}$, with more serious underestimations and estimation errors increased under this condition. Compared with daily LE obtained under the hypothetical clear-sky condition, the upscaled daily LE for cloudy-sky days was reduced. The variations of the daily LE over time complied with a periodicity law and may result from seasonal variations of total shortwave solar radiations.

\section{ACKNOWLEDGEMENT}

The work was supported by the National Natural Science Foundation of China (No. 41571351, 41571352, 41571367 and 41231170), the International Science and Technology Cooperation Program of China (No. 2014DFE10220), the National Basic Research Program of China (973 Program) (No. 2013CB733402) and the grant of China Scholarship Council.

\section{REFERENCES}

Anderson, M. C., Kustas, W. P., Alfieri, J. G., Gao, F., Hain, C., Prueger, J. H., and Chávez, J. L. (2012). Mapping daily evapotranspiration at Landsat spatial scales during the BEAREX'08 field campaign. Advances in Water Resources, 50, 162-177. doi: 10.1016/j.advwatres.2012.06.005.

Barzin, R., Shirvani, A., and Lotfi, H. (2017). Estimation of daily average downward shortwave radiation from MODIS data using principal components regression method: Fars province case study. International Agrophysics, 31(1), 23-34. doi: 10.1515/intag-2016-0035.

Bastiaanssen, W. G. M. (2000). SEBAL-based sensible and latent heat fluxes in the irrigated Gediz Basin, Turkey. Journal of hydrology,229(1), 87-100. doi: 10.1016/S00221694(99)00202-4.

Bastiaanssen, W. G., Menenti, M., Feddes, R. A., and Holtslag, A. A. M. (1998). A remote sensing surface energy balance algorithm for land (SEBAL). 1. Formulation. Journal of hydrology, 212, 198-212. doi: 10.1016/S0022-1694(98)00254-6. 
Berg, L. K., Kassianov, E. I., Long, C. N., and Mills, D. L. (2011). Surface summertime radiative forcing by shallow cumuli at the Atmospheric Radiation Measurement Southern Great Plains site.Journal of Geophysical Research: Atmospheres, 116(D1). doi: 10.1029/2010JD014593.

Bisht, G., Venturini, V., Islam, S., and Jiang, L. E. (2005). Estimation of the net radiation using MODIS (Moderate Resolution Imaging Spectroradiometer) data for clear sky days. Remote Sensing of Environment, 97(1), 52-67. doi: 10.1016/j.rse.2005.03.014.

Boegh, E., Soegaard, H., and Thomsen, A. (2002). Evaluating evapotranspiration rates and surface conditions using Landsat TM to estimate atmospheric resistance and surface resistance. Remote Sensing of Environment, 79(2), 329-343. doi: 10.1016/S0034-4257(01)00283-8.

Brutsaert, W., and Sugita, M. (1992). Application of self - preservation in the diurnal evolution of the surface energy budget to determine daily evaporation. Journal of Geophysical Research: Atmospheres,97(D17), 18377-18382. doi: 10.1029/92JD00255.

Bussieres, N. and Goita, K. (1997). Evaluation of strategies to deal with cloudy situation in satellite evapotranspiration algorithm. Proceedings of the third International Workshop NHRI symposium 17, 16-18 October 1996, NASA, Goodard Space Flight Center, Greenbelt, Maryland, USA: 33-43.

Cammalleri, C., Anderson, M. C., and Kustas, W. P. (2014). Upscaling of evapotranspiration fluxes from instantaneous to daytime scales for thermal remote sensing applications. Hydrology and Earth System Sciences, 18(5), 1885-1894. doi: 10.5194/hess-18-1885-2014.

Chávez, J. L., Neale, C. M., Prueger, J. H., and Kustas, W. P. (2008). Daily evapotranspiration estimates from extrapolating instantaneous airborne remote sensing ET values. Irrigation Science, 27(1), 67-81. doi: 10.1007/s00271-008-0122-3.

Chinese terrestrial ecosystem flux research network. http://www.Chinaflux.org/.

Crago, R.D. (1996). Conservation and variability of the evaporative fraction during the daytime. Journal of Hydrology, 180(1-4), 173-194. doi: 10.1016/0022-1694(95)02903-6.

Delogu, E., Boulet, G., Olioso, A., Coudert, B., Chirouze, J., Ceschia, E., and Lagouarde, J. P. (2012). Reconstruction of temporal variations of evapotranspiration using instantaneous estimates at the time of satellite overpass. Hydrology and Earth System Sciences, 16, 2995-3010. doi: 10.5194/hess-16-2995-2012.

Foken, T. (2008). The energy balance closure problem: an overview. Ecological Applications, 18(6), 1351-1367. doi: 10.1890/06-0922.1.

Hou, J., Jia, G., Zhao, T., Wang, H., and Tang, B. (2014). Satellite-based estimation of daily average net radiation under clear-sky conditions. Advances in Atmospheric Sciences, 31(3), 705. doi: 10.1007/s00376-013-3047-6.

Jackson, R. D., Hatfield, J. L., Reginato, R. J., Idso, S. B., and Pinter, P. J. (1983). Estimation of daily evapotranspiration from one time-of-day measurements. Agricultural Water Management, 7(1-3), 351-362. doi: 10.1016/0378-3774(83)90095-1. 
Li, Z. L., Tang, R., Wan, Z., Bi, Y., Zhou, C., Tang, B., and Zhang, X. (2009). A review of current methodologies for regional evapotranspiration estimation from remotely sensed data. Sensors,9(5), 3801-3853. doi: 10.3390/s90503801.

Long, C. N., and Ackerman, T. P. (2000). Identification of clear skies from broadband pyranometer measurements and calculation of downwelling shortwave cloud effects. Journal of Geophysical Research: Atmospheres, 105(D12), 15609-15626. doi: 10.1029/2000JD900077.

Long, C. N., Ackerman, T. P., Gaustad, K. L., and Cole, J. N. S. (2006). Estimation of fractional sky cover from broadband shortwave radiometer measurements. Journal of Geophysical Research: Atmospheres, 111(D11). doi: 10.1029/2005JD006475.

Mallick, K., Jarvis, A., Wohlfahrt, G., Kiely, G., Hirano, T., Miyata, A., and Hoffmann, L. (2015). Components of near-surface energy balance derived from satellite soundings-Part 1: Noontime net available energy. Biogeosciences, 12(2), 433-451. doi: 10.5194/bg-12-433-2015.

Mayer, B., and Kylling, A. (2005). The libRadtran software package for radiative transfer calculations-description and examples of use. Atmospheric Chemistry and Physics, 5(7), 18551877. doi: 10.5194/acp-5-1855-2005, 2005.

Ryu, Y., Baldocchi, D. D., Black, T. A., Detto, M., Law, B. E., Leuning, R., and Beringer, J. (2012). On the temporal upscaling of evapotranspiration from instantaneous remote sensing measurements to 8-day mean daily-sums. Agricultural and Forest Meteorology, 152, 212-222. doi: 10.1016/j.agrformet.2011.09.010.

Salgueiro, V., Costa, M. J., Silva, A. M., and Bortoli, D. (2014). Variability of the daily-mean shortwave cloud radiative forcing at the surface at a midlatitude site in Southwestern Europe. Journal of Climate, 27(20), 7769-7780. doi: 10.1175/JCLI-D-13-00696.1.

Tang, B., and Li, Z. L. (2008). Estimation of instantaneous net surface longwave radiation from MODIS cloud-free data. Remote Sensing of Environment,112(9), 3482-3492. doi: 10.1016/j.rse.2008.04.004.

Tang, R., Li, Z. L., and Sun, X. (2013). Temporal upscaling of instantaneous evapotranspiration: An intercomparison of four methods using eddy covariance measurements and MODIS data. Remote sensing of environment, 138, 102-118. doi: 10.1016/j.rse.2013.07.001.

Tang, R., Li, Z. L., Sun, X., and Bi, Y. (2017a). Temporal upscaling of instantaneous evapotranspiration on clear - sky days using the constant reference evaporative fraction method with fixed or variable surface resistances at two cropland sites. Journal of Geophysical Research: Atmospheres, 122(2), 784-801. doi: 10.1002/2016JD025975.

Tang, R., and Li, Z. L. (2017b). An improved constant evaporative fraction method for estimating daily evapotranspiration from remotely sensed instantaneous observations. Geophysical Research Letters, 44(5), 2319-2326. doi: 10.1002/2017GL072621.

Twine, T. E., Kustas, W. P., Norman, J. M., Cook, D. R., Houser, P. R., Meyers, T. P., Prueger, J. H., Starks, P. J., and Wesely, M. L. (2000). Correcting eddy-covariance flux underestimates 
over a grassland. Agricultural and Forest Meteorology, 103(3), 279-300. doi: 10.1016/S01681923(00)00123-4.

Van Niel, T. G., McVicar, T. R., Roderick, M. L., van Dijk, A. I., Beringer, J., Hutley, L. B., and Van Gorsel, E. (2012). Upscaling latent heat flux for thermal remote sensing studies: Comparison of alternative approaches and correction of bias. Journal of hydrology, 468, 35-46. doi: 10.1016/j.jhydrol.2012.08.005.

Wandera, L., Mallick, K., Kiely, G., Roupsard, O., Peichl, M., and Magliulo, V. (2017). Upscaling instantaneous to daily evapotranspiration using modelled daily shortwave radiation for remote sensing applications: an artificial neural network approach. Hydrology and Earth System Sciences, 21(1), 197. doi: 10.5194/hess-21-197-2017.

Xu, T., Liu, S., Xu, L., Chen, Y., Jia, Z., Xu, Z., and Nielson, J. (2015). Temporal upscaling and reconstruction of thermal remotely sensed instantaneous evapotranspiration. Remote Sensing, 7(3), 3400-3425. doi: 10.3390/rs70303400.

\section{Figure captions}

Figure 1. The location of the Yucheng station

Figure 2. The measured and normalized daytime shortwave irradiance (20 May 2009)

Figure 3. An illustration of irradiance variations with time (24 May 2009)

Figure 4. Comparison of the estimated instantaneous LE and the measured LE corrected with the BR method for partly cloudy-sky and selected clear-sky days before (a) and after (b) the instantaneous LE at partly cloudy-sky days was corrected by the linear regression

Figure 5. Comparison of the upscaled daily LE and the measured value corrected with the BR method under partly cloudy-sky and selected clear-sky conditions

Figure 6. Histograms of the biases related to upscaling results under selected clear-sky and partly cloudy-sky conditions

Figure 7. Comparison of the daily LE of partly cloudy-sky days and corresponding hypothetical clear-sky days 
$50^{\circ} 0^{\prime} 0^{\prime \prime} \mathrm{N}-$

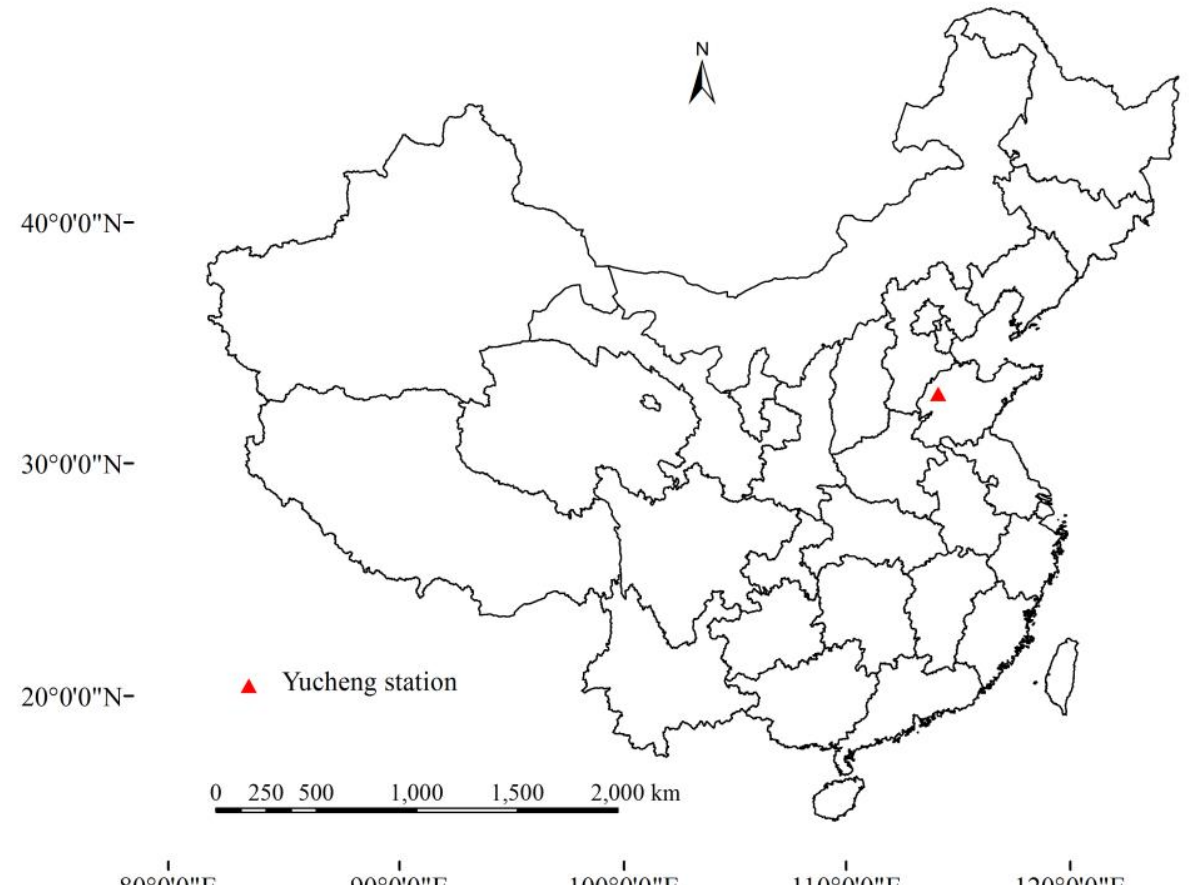

$80^{\circ} 0^{\prime} 0^{\prime \prime} \mathrm{E} \quad 90^{\circ} 0^{\prime} 0^{\prime \prime} \mathrm{E} \quad 100^{\circ} 0^{\prime} 0^{\prime \prime} \mathrm{E} \quad 110^{\circ} 0^{\prime} 0^{\prime \prime} \mathrm{E} \quad 120^{\circ} 0^{\prime} 0^{\prime \prime} \mathrm{E}$

Figure 1

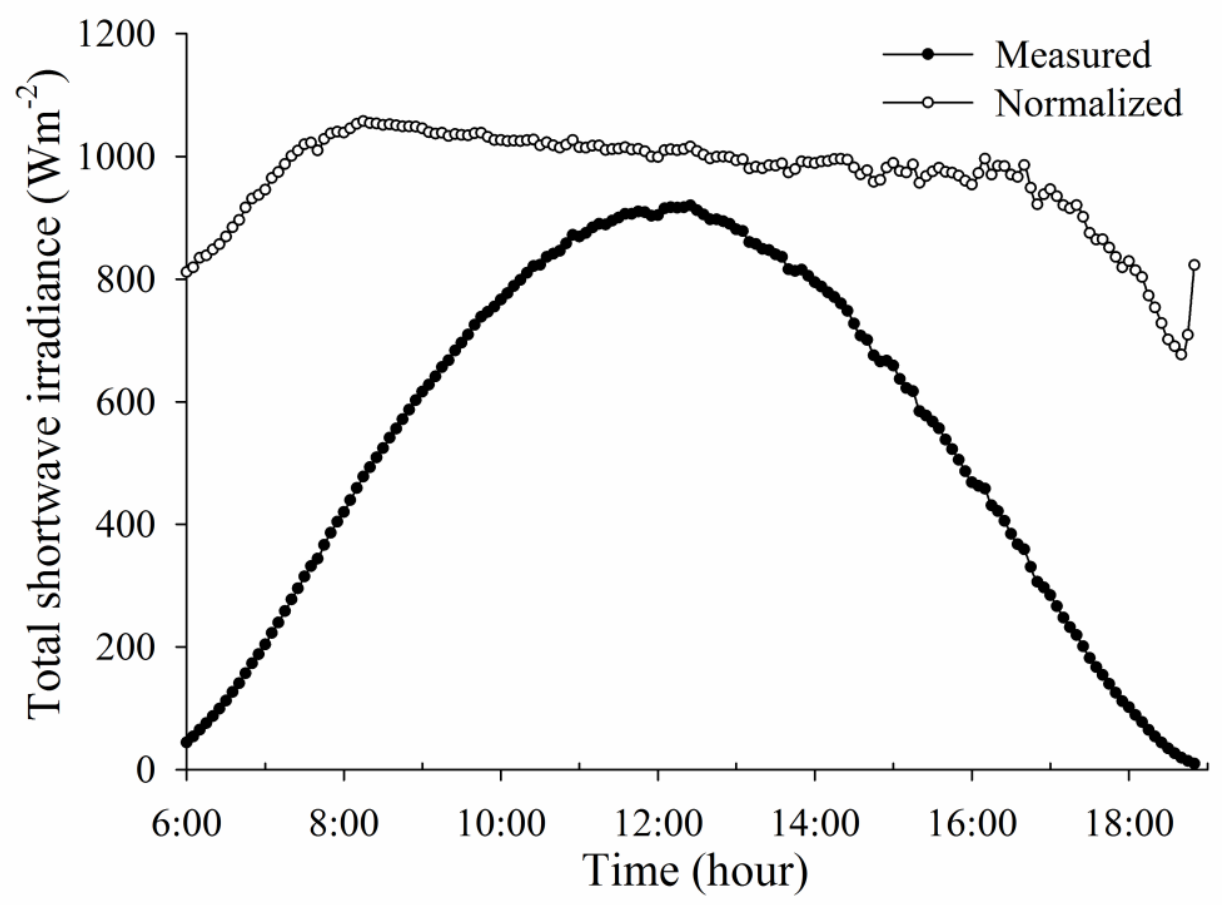

Figure 2 


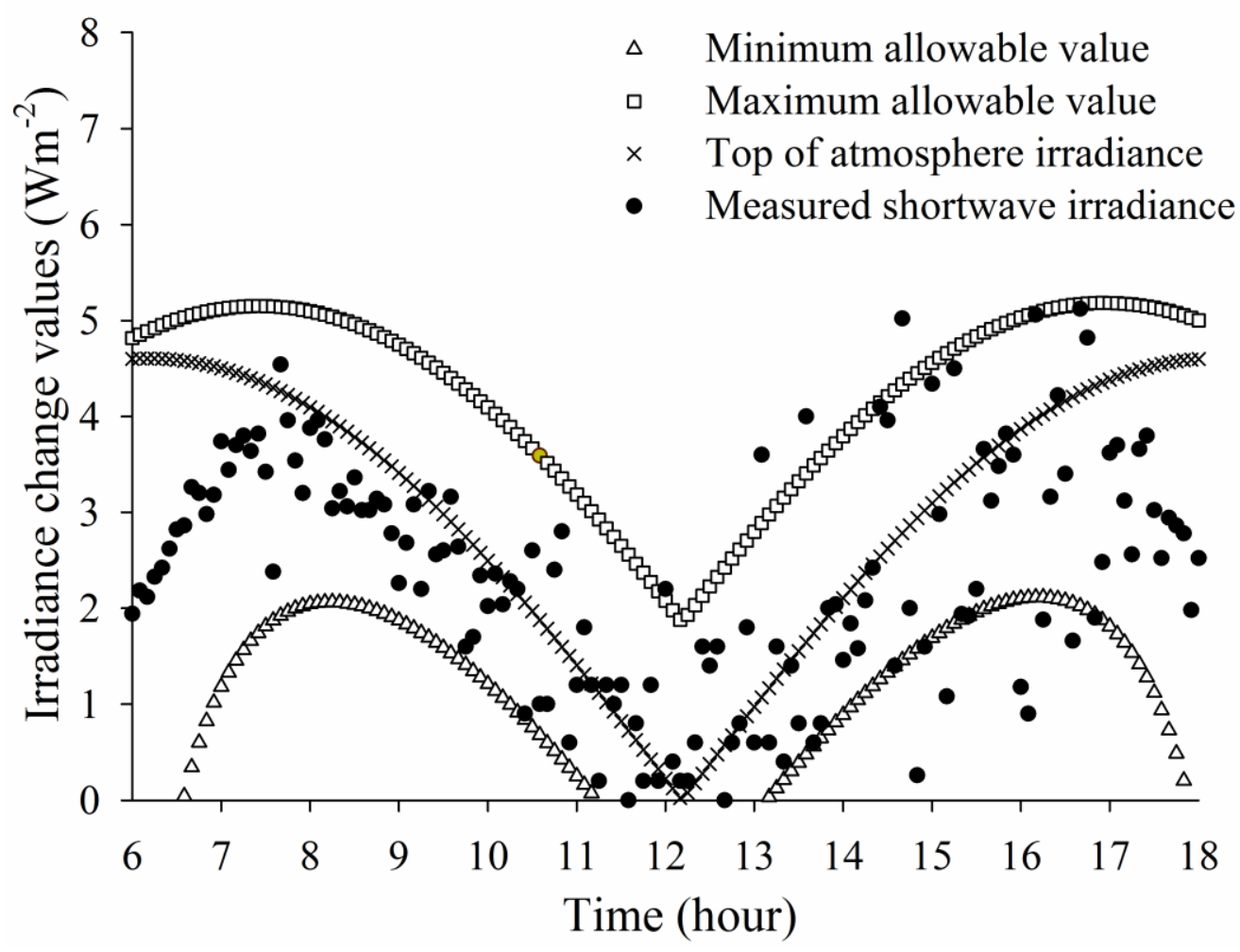

Figure 3 

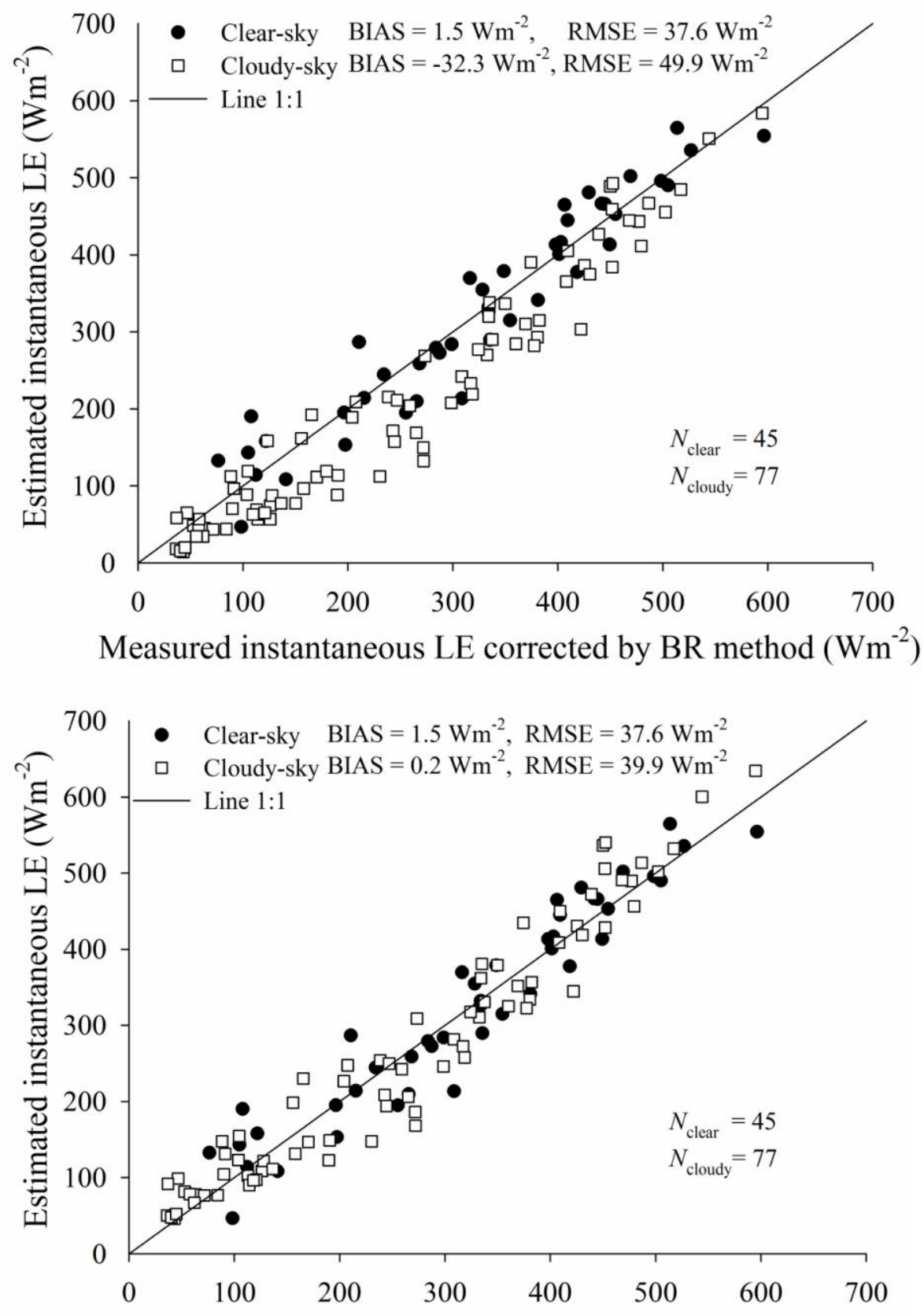

(b) Measured instantaneous LE corrected by BR method $\left(\mathrm{Wm}^{-2}\right)$

Figure 4 


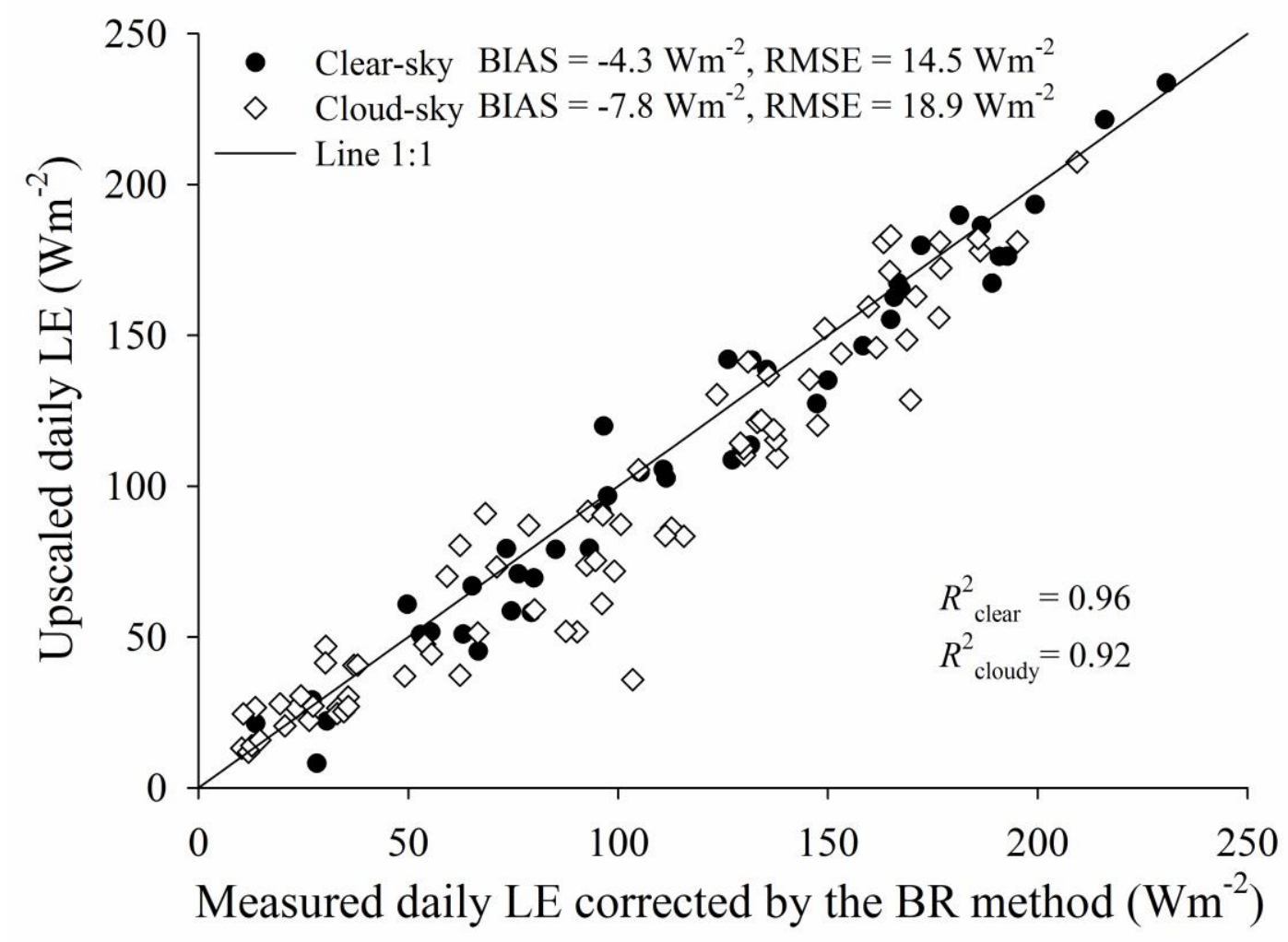

Figure 5

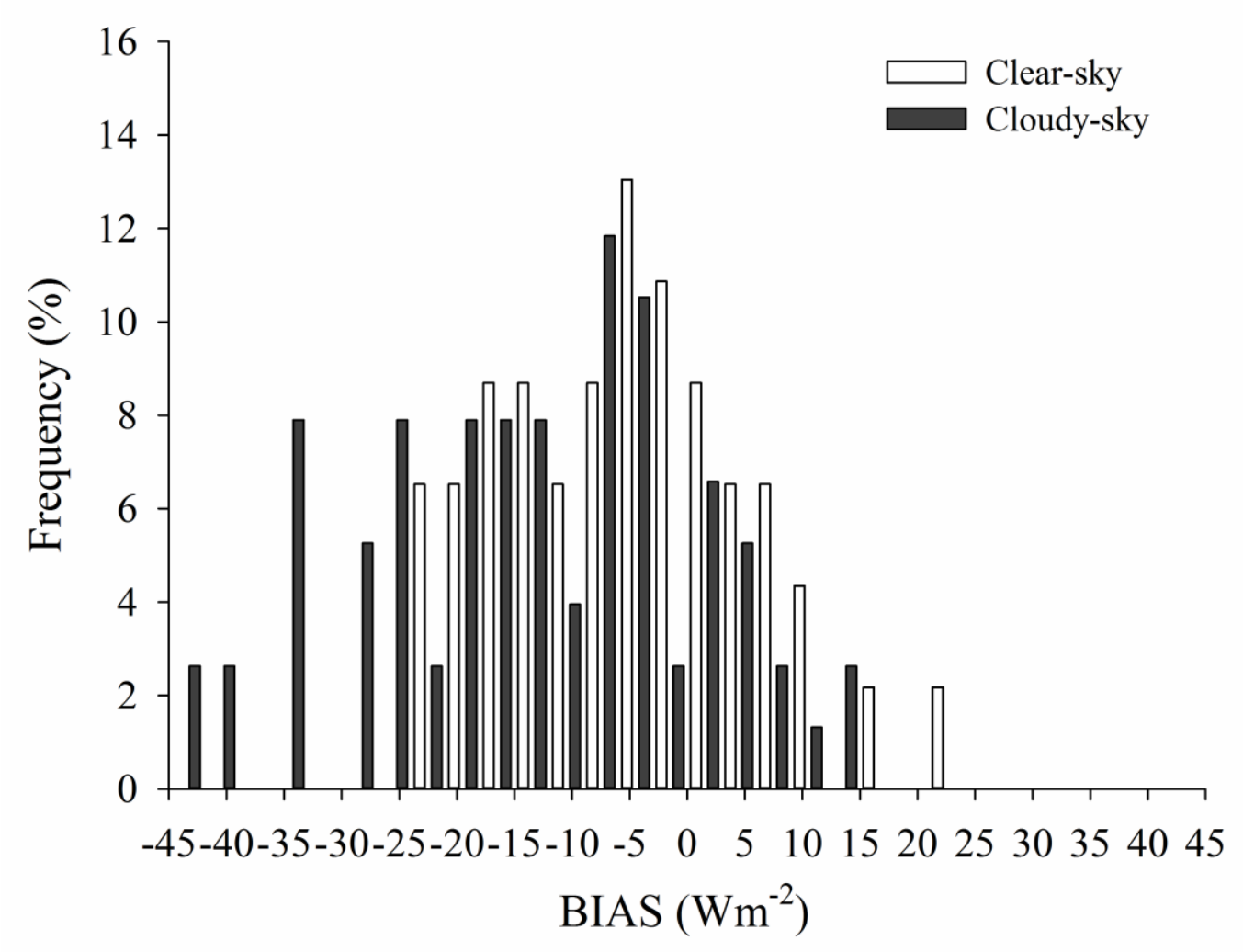

Figure 6 


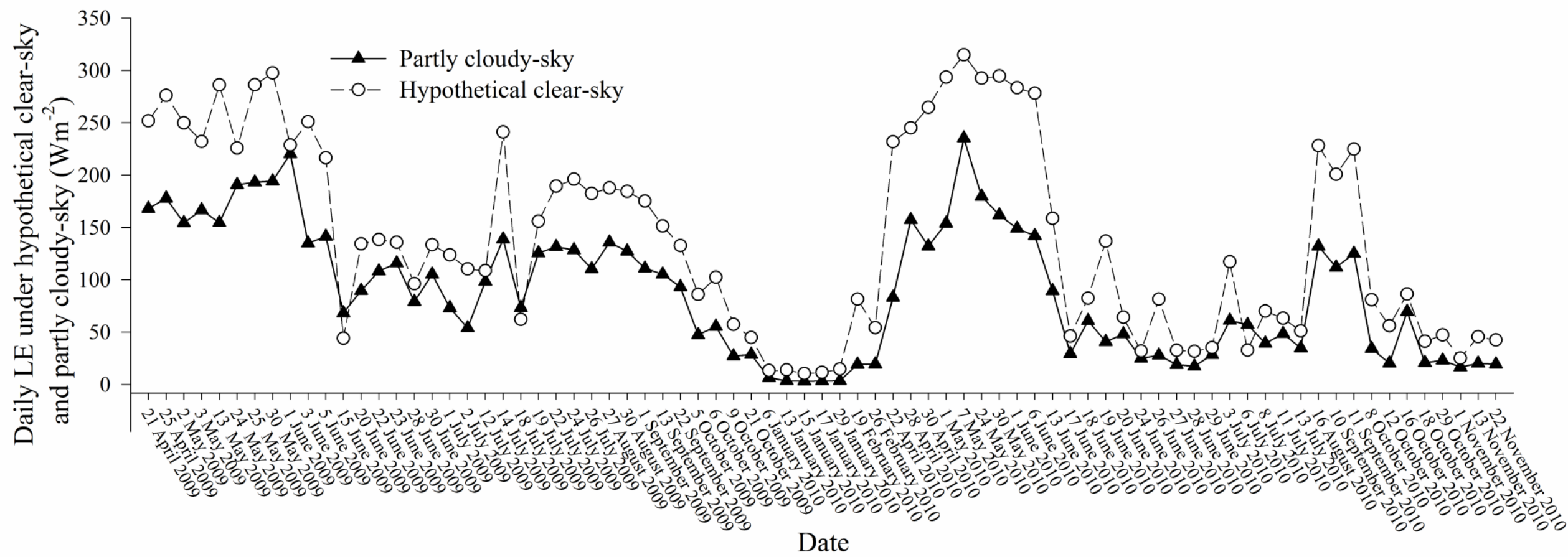

Figure 7 